${ }^{1}$ DDS, MS, PhD Student in

Restorative Dentistry, Department of Restorative Dentistry, Piracicaba Dental School, State University of Campinas, Piracicaba, SP, Brazil.

${ }^{2}$ DDS, MS, PhD in Restorative Dentistry, Department of Restorative Dentistry, Piracicaba Dental School, State University of Campinas, Piracicaba, SP, Brazil.

${ }^{3}$ DDS, MS, PhD Student in Restorative Dentistry, Department of Restorative Dentistry, Piracicaba Dental School, State University of Campinas, Piracicaba, SP, Brazil.

${ }^{4}$ DDS, MS, PhD Student in Restorative Dentistry, Department of Restorative Dentistry, Piracicaba Dental School, State University of Campinas, Piracicaba, SP, Brazil.

${ }^{5}$ DDS, MS, PhD, Titular Professor of Department of Exact Sciences, Luiz de Queiroz College of Agriculture, University of São Paulo, Piracicaba, SP, Brazil

${ }^{6}$ DDS, MS, PhD, Titular Professor of Department of Restorative Dentistry, Piracicaba Dental School, State University of Campinas, Piracicaba, SP-Brazil.

Corresponding author:

Lúcia Trazzi Prieto

Piracicaba Dental School - State University of Campinas - UNICAMP Department of Restorative Dentistry Dental Materials Area

901 Avenida Limeira, Areião, Piracicaba, Sao Paulo, Brazil. 13414-018.

Telephone: +55 19 98408-8800

E-mail: lucinhatrazzi@hotmail.com

Received: September 05, 2017 Accepted: December 01, 2017

\section{Influence of whitening dentifrices and mechanical brushing on color change and surface roughness of bulk fill resins}

\author{
Mayara Zaghi Dal Picolo', Lúcia Trazzi Prieto², Josué \\ Junior Araujo Pierote ${ }^{3}$, Suelem Chasse Barreto ${ }^{4}$, \\ Carlos Tadeu dos Santos Dias ${ }^{5}$, Luís Alexandre \\ Maffei Sartini Paulillo ${ }^{6}$
}

The use of whitening dentifrices during oral hygiene may cause surface modifications such as color change $(\Delta E)$ and increase surface roughness $(\mathrm{Ra})$ of composite resin. Aim: This study aimed to evaluate the effect of whitening dentifrices and mechanical brushing on color change and surface roughness of Bulk Fill (Filtek Bulk Fill - F) and (Aura Bulk Fill - A) composite resins. Materials and methods: Sixty cylindrical specimens were fabricated of each composite resin. After initial color evaluations (Konica Minolta CM-700d), with D65 standard illuminant, and the surface roughness (Surfcorder SE 1700, Kosalab), the specimens were assigned $(n=10)$ according to the whitening dentifrice used: True White (T), Colgate Total 12 Professional Whitening (D), Luminous White Advanced $(L)$. Specimens were submitted to mechanical brushing (10,000 cycles); new color and surface roughness evaluations were taken. Data were analyzed by ANOVA, Duncan test and Dunnet test were used to identify differences between groups $(\alpha=5 \%)$. Results: The results showed that the tooth brushing time promoted a significant increase in $\Delta \mathrm{E}$ of the FT group. The FD group exhibited intermediate values of $\Delta \mathrm{E}$ and was similar to all groups tested. There was a significant increase in the surface roughness of the AD and AT groups after the mechanical tooth brushing. Conclusion: The results showed no significant changes were observed in surface roughness for $F$ groups after toothbrushing. It be concluded that the color change and surface roughness of the composite resins after toothbrushing are dependent on the interaction between the composition of the composite resin and the characteristics of the dentifrice.

Keywords: Composite Resins. Toothbrushing. Dentifrices. Color. 


\section{Introduction}

Composite resin has been widely used in procedures that require the restoration of the shape, function and aesthetics of the dental element, due to its physical and chemical properties. In addition, composites mimic the color, translucence and dental texture, and provide mechanical resistance similar to the healthy dental tissues ${ }^{1}$.

The most used technique in direct restorations with composite resins is the incremental technique, since it minimizes the effects of the polymerization contraction. Nevertheless, this technique considerably increases the clinical time to perform the restorative procedure ${ }^{2,3}$. With the aim of simplifying the restorative procedure, with no damages to the composite performance, Bulk Fill composite resins were introduced in the market $^{4,5}$. This composite category has alternative photoinitiators, such as monoacylphosphine oxide or dibenzoyl germanium derivatives that, when exposed to light, promote an unimolecular reaction more efficient than camphorquinone and have the potential to increase the cure depth, allowing the use of increments 4 to $5 \mathrm{~mm}^{6,7}$.

On the other hand, composite resins present limitations, especially regarding the maintenance of their characteristics over time. The decrease of the composites mechanical properties, due to buccal environment adverse conditions, such as temperature and $\mathrm{pH}$ changing, wear promoted by masticatory movements and brushing affect mainly the surface smoothness and the original color of the composites ${ }^{8}$.

The use of dentifrice is essential for maintenance of oral health. Besides having therapeutic function, acting as a vehicle for the incorporation of fluoride in buccal environment, which has proven action in the reduction of caries, dental brushing, when associated with dentifrice, favors the mechanical removal of biofilm, as well as the removal of pigments from the teeth and restorations ${ }^{9}$.

When dental brushing is associated with a whitening dentifrice, dental tissues and restorations polishing may be damaged, due to higher concentration of abrasive particles responsible for the superficial removal of stains and enzymatic disintegration of organic molecules present in the biofilm. Additionally, some whitening dentifrices have concentrations of hydrogen peroxide ( 1 to $2 \%$ ). Changes on the composite surface may be related to this agent ${ }^{10,11}$.

Dental toothbrushing with dentifrices affects the color and surface roughness of conventional composite resins ${ }^{8,12}$. Its effect on the composites roughness is significant in determining the performance of the material, once the dentifrice relative abrasiveness may increase the surface porosity and remove the composite fillers, inducing water sorption. This results in color changing and loss of brightness and influences the surface smoothness.

However, there is little evidence in the literature regarding the action of whitening dentifrices on the surface roughness, color changing of Bulk Fill composites, and the aging of the composites through simulated mechanical brushing proves to be a valid method to evaluate the behavior of this class of restorative material ${ }^{8,13}$.

Therefore, this in vitro study aims to evaluate the behavior of two Bulk Fill composites when subjected to simulated mechanical brushing using whitening dentifrices. 


\section{Materials and Methods}

In the present study two Bulk fill composite resins, shade A3, and three whitening dentifrices were used for the brushing of the samples (Table 1).

Twenty specimens of each Bulk-fill resin (F or A) were obtained using a bipartite Teflon matrix $(7.0 \mathrm{~mm}$ diameter and $5.0 \mathrm{~mm}$ tick). The cavity mold was filled in a single increment. After inserting the composite in the mold, the increment was covered with a glass slide with minor digital pressure was placed on the composite resin increment and a weight of 500 grams for 1 minute to obtain a flat and regular surface. The specimens were photoactivated for 40 seconds using a LED light-emitting source (VALO, Ultradent Products Inc., S. Jordan, UT, USA-1400mW / cm2) according to manufacturers recommendations. After, the specimen was detached from the mold and the excess resin runoff with a 15 -scalpel blade and stored in distilled water at $37^{\circ} \mathrm{C}$ for

Table 1. Composition and manufacturers of Bulk Fill composites and dentifrices used in color change and surface roughness tests.

\begin{tabular}{|c|c|c|c|c|}
\hline Material & Manufacturer & Composition & Particle Size & $\begin{array}{l}\% \text { Filler } \\
\text { (by vol) }\end{array}$ \\
\hline Filtek Bulk Fill & $\begin{array}{c}\text { 3M ESPE } \\
\text { St Paul, MN, USA }\end{array}$ & $\begin{array}{l}\text { Ceramics treated with silane, UDMA, } \\
\text { aromatic Dimethacrylate Uretane, Silica } \\
\text { treated with silane, Itibérbio fluoride, } \\
\text { DDMA, Zirconia treated with silane, } \\
\text { Water, Monomer AFM-1, EDMAB, } \\
\text { Benzotriazole, Doxido of titanium. }\end{array}$ & $\begin{array}{l}\text { 20nm silica } \\
\text { filler, } 4 \\
\text { to } 11 \mathrm{~nm} \\
\text { zirconia filler, } \\
\text { and } 100 \mathrm{~nm}\end{array}$ & $\begin{array}{c}76.5 \% / \\
58.4 \%\end{array}$ \\
\hline AURA Bulk Fill & $\begin{array}{c}\text { SDI Bayswater, } \\
\text { Australia }\end{array}$ & $\begin{array}{c}\text { Barium aluminosilicate pre-polymerized } \\
\text { filler; improved optical properties; } \\
\text { Amorphous silicon dioxide; UDMA/ } \\
\text { BisEMA/BisGMA }\end{array}$ & $\begin{array}{l}0.02 \text { micron } \\
-0.4 \text { micron } \\
\text { fillers }\end{array}$ & $\begin{array}{c}81 \% \text { wt filled, } \\
65 \% \text { vol }\end{array}$ \\
\hline True White & $\begin{array}{c}\text { Sensodyne } \\
\text { Glaxosmithkline }\end{array}$ & $\begin{array}{l}\text { Sodium fluoride; Potassium nitrate 5\%; } \\
\text { Triofosfato pentasódio 5\%; Sorbitol; } \\
\text { Glycerine; Hydrated silica; water; PEG-6; } \\
\text { Cocamidopropyl bataine; (d- limonene } \\
\text { e cinnamal) arome; Dióxido de titânio; } \\
\text { Xantana gun; Sodium saccharin; } \\
\text { Sodium hydroxid. }\end{array}$ & - & - \\
\hline $\begin{array}{l}\text { Colgate Total } \\
12 \text { Professional } \\
\text { Whitening }\end{array}$ & $\begin{array}{l}\text { Colgate Palmolive } \\
\text { Company,Osasco, } \\
\text { SP, Brasil }\end{array}$ & $\begin{array}{l}\text { Water; Sorbitole; Hydrated silica; } \\
\text { Glicerine; Sodium Lauryl sulfate; } \\
\text { Fluoruro sodium; PVM/MA copolymer; } \\
\text { Sodium hydroxid; Propilenglicol; } \\
\text { Cellulose gun; Triclosano; Sodium } \\
\text { Saccharin; Carrageenin; Titanium } \\
\text { dioxide; Sodium fluoride. }\end{array}$ & - & - \\
\hline $\begin{array}{l}\text { Luminous White } \\
\text { Advanced }\end{array}$ & $\begin{array}{c}\text { Colgate Palmolive } \\
\text { Company, Osasco, } \\
\text { SP, Brasil }\end{array}$ & $\begin{array}{l}\text { Hydrogen peroxide 1\%; Sodium } \\
\text { monofluorephosphate 0,76\%; Propylene } \\
\text { glicol; Calico pirephosphatte; Glicerine, } \\
\text { PEG; PPG- 116; } 66 \text { Copolymer; PEG -12; } \\
\text { PVP- Hydrogen peroxide; PVP; Silica; } \\
\text { Tetrasodium pirophosphate ; Sodium } \\
\text { Lauril Sulfate; Disodium pirophosphate } \\
\text {; Sodium sacarine; Sucralose; BHT; } \\
\text { EugenolPirofosfato dissódico; Sacarina } \\
\text { Sódica; Sucralose; BHT; Eugenol }\end{array}$ & & \\
\hline
\end{tabular}


24 hours. Afterwards, the surface of each specimen was polished (Polishing machine, APL-4; Arotec, SP, Brazil) with silicon carbide (SIC) papers of decreasing abrasiveness (\#2000 and \#4000 grit) (CARBIMET Paper Discs; Buehler, IL, USA) for 1 minute.

Subsequently, initial color readouts (baseline) were (Konica Minolta CM-700d, Konica Minolta Investment Ltd. Sensing Business Division, Shanghai, China) was then calibrated according to the manufacturer's instructions. The specimens were placed in a Teflon device (sample port), with D65 standard illuminant, to standardize the environment during the readings.

Next, surface roughness (baseline) was obtained in three measurements (Surfcorder SE 1700, Kosalab), cut-off of $0.8 \mathrm{~mm}$ and speed of $0.25 \mathrm{~mm} / \mathrm{s}$. The specimens were positioned parallel to the surface of the equipment, each sample being fixed to an acrylic base and the measuring tip positioned on the sample surface. After each reading, the sample was rotate $120^{\circ}$, thus the three readings would be passed over the same point in the center of the sample.

The initial (baseline) roughness of Bulk Fill Filtek and Aura were used as controls for the statistical analysis

After the initial readings of color and roughness, the 30 specimens of each Bulk Fill resin were randomly divided according to the interaction Bulk Fill $x$ Whitening dentifrice used: True White (T), Colgate Total 12 Professional Whitening (D) and Luminous White Advanced $(\mathrm{L})$, totaling 6 experimental groups $(\mathrm{n}=10)$ : Filtek Bulk Fill / True White (FT), Filtek Bulk Fill / Total 12 Professional Whitening (FD), AURA Bulk Fill / Total 12 Professional Whitening (AD), Filtek Bulk Fill / Luminous White Advanced (FL), AURA Bulk Fill / Luminous White Advanced (AL) and AURA Bulk Fill / True White (AT).

Mechanical brushing was performed with 60 soft toothbrushes (Oral B Indicator Plus - Procter \& Gamble) one per specimen. The toothbrush head were cut off and attached to the brush holder device of the brushing machine MSet (Marcelo Nucci ME, São Carlos, Brazil), by means of thermal glue (Brascola, São Bernardo do Campo, SP, Brazil) so that the toothbrush head was parallel and in contact with the surface of the specimen. In this equipment it was possible to perform the simultaneous brushing of ten specimens at the same time. For brushing of each test specimen, a quantity of $8 \mathrm{~g}$ of dentifrice was mixed with $24 \mathrm{ml}$ of distilled water, measured on analytical balance and precision pipette, forming slurry with a ratio of $1: 3$ by mass for the dilution of the dentifrice.

Each specimen was submitted to a total of 10,000 cycles of linear brushing movements, at a frequency of $4 \mathrm{~Hz}$, under a load of $200 \mathrm{~g}$, to simulate the force used during oral hygiene procedures ${ }^{13}$.

After this, the machine was switched off, the specimens were removed from the machine, rinsed in distilled water and dried with absorbent paper to remove surface debris (Kleenex - Kimberly-Clark, São Paulo, SP, Brazil) and submitted to a new color and surface roughness measurements.

The color measurements were taken and the color change for each different group was calculated by CIE Lab system in three coordinates to allow the calculation of the color variation $(\Delta \mathrm{E})$, using the following formula:

$$
\left.\Delta \mathrm{E}=[\mathrm{L} 1-\mathrm{LO})^{2}+(\mathrm{a} 1-\mathrm{a} 0)^{2}+(\mathrm{b} 1-\mathrm{b} 0)^{2}\right]^{1 / 2} .
$$


Surface roughness alteration ( $\mathrm{Ra}$ ) was calculated using the formula:

$$
\mathrm{Ra}=R \mathrm{a}_{\mathrm{f}}-\mathrm{Ra}_{\mathrm{i}}
$$

where $\mathrm{Ra}_{\mathrm{i}}$ is the initial and $\mathrm{Ra}_{\mathrm{f}}$ the final roughness measurement.

\section{Results}

Statistical analysis: After checking the normality of the results, for the color variation was applied one-way Anova and Duncan's test. For the surface roughness the Dunnet's test (SAS) was applied and the $5 \%$ probability limit was adopted for decision making for both statistical analyzes.

\section{Color change}

The data obtained in the color variation test $(\Delta \mathrm{E})$ were submitted to the normality test (Shapiro Wilk), which indicated discrepant values, so the data were transformed, increasing to the 0.2 powers that corrected the problems. Thus ANOVA one-way was applied and showed that there was significant statistical difference between the studied groups and Duncan's test was applied to evidence this result that is presented in table 2.

Table 2. Mean (M), Standard Deviation (DV) and Duncan (D) test result (5\%) for the Color Variation $(\Delta E)$, $\Delta \mathrm{L}, \Delta \mathrm{a}$ and $\Delta \mathrm{b}$ of Bulk Fill composite resins.

\begin{tabular}{cccccc}
\hline Groups & $\mathbf{N}$ & $\Delta \mathrm{E}$ & $\Delta \mathrm{L}$ & $\Delta \mathbf{a}$ & $\Delta \mathbf{b}$ \\
\hline $\mathrm{FT}$ & 10 & $2.57(1.42)^{\star}$ & $0.61(0.03)^{\mathrm{a}}$ & $0.11(0.04)^{\mathrm{b}}$ & $1.26(0.29)^{\mathrm{c}}$ \\
\hline $\mathrm{FD}$ & 10 & $1.53(0.78)^{\star / \star \star}$ & $0.77(0.05)^{\mathrm{a}}$ & $0.28(0.10)^{\mathrm{b}}$ & $0.35(0.11)^{\mathrm{c}}$ \\
\hline $\mathrm{FL}$ & 10 & $1.46(0.75)^{\star \star \star}$ & $0.54(0.05)^{\mathrm{a}}$ & $0.15(0.02)^{\mathrm{b}}$ & $0.09(0.14)^{\mathrm{c}}$ \\
\hline $\mathrm{AT}$ & 10 & $1.17(0.54)^{\star \star \star}$ & $0.07(0.40)^{\mathrm{a}}$ & $0.35(0.07)^{\mathrm{b}}$ & $0.25(0.04)^{\mathrm{c}}$ \\
\hline $\mathrm{AD}$ & 10 & $1.16(0.67)^{\star \star \star}$ & $0.51(0.07)^{\mathrm{a}}$ & $0.10(0.01)^{\mathrm{b}}$ & $0.55(0.07)^{\mathrm{c}}$ \\
\hline $\mathrm{AL}$ & 10 & $1.12(0.74)^{\star \star \star}$ & $0.14(0.02)^{\mathrm{a}}$ & $0.12(0.05)^{\mathrm{b}}$ & $0,53(0.06)^{\mathrm{c}}$ \\
\hline
\end{tabular}

$\mathrm{a}, \mathrm{b}, \mathrm{c}$ Equal letters show that there is no significant difference between the means and standard deviation of $\Delta \mathrm{L}$, $\Delta \mathrm{a}$ and $\Delta \mathrm{b}$ compared by lines.

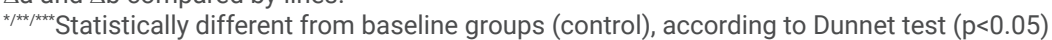

F= Filtek Bulk Fill; $A=$ AURA Bulk Fill; $T=$ True White; $D=$ Colgate Total 12 Professional Whitening; $L=$ Luminous White Advanced

The results for the Duncan test showed that the Filtek Bulk Fill resin brushed with the Sensodyne True White (FT) showed higher color variation compared to the FL, AT, AD and $\mathrm{AL}$ groups. The FD group presented intermediate values, with no statistical difference in relation to all the experimental groups. The results of $\Delta \mathrm{L}, \Delta \mathrm{a}$ and $\Delta \mathrm{b}$ did not differ statistically between the different groups.

\section{Surface roughness}

The Filtek Bulk Fill and Aura Bulk Fill were not compared with each other. They were compared only with to control (the same composite resin without treatment).

The results of the Dunnet test for the roughness test showed that only A when brushed with $\mathrm{D}$ and $\mathrm{T}$ presented significant statistical difference for its control, that is, for the roughness before brushing. While F presented no significant statistical difference for its control when brushed with the whitening toothpaste (table 3). 
Table 3. Results of the Dunnet test for the surface roughness test of Bulk Fill composites after brushing with bleaching dentifrices.

\begin{tabular}{cccc}
\hline Groups & N & Mean (DV) & Dunnett \\
\hline Baseline A & 30 & $0.079(0.007)$ & \\
\hline AD & 10 & $0.143(0.035)$ & \\
\hline AL & 10 & $0.098(0.026)$ & $* * *$ \\
\hline AT & 10 & $0.124(0.039)$ & \\
\hline Baseline F & 30 & $0.071(0.006)$ & \\
\hline FD & 10 & $0.088(0.021)$ & \\
\hline FL & 10 & $0.075(0.009)$ & \\
\hline FT & 10 & $0.084(0.044)$ & \\
\hline
\end{tabular}

$\star \star \star$ Statistically different from baseline groups (control), according to Dunnet test $(p<0.05)$

F= Filtek Bulk Fill; $A=$ Aura Bulk Fill; $T=$ True White; $D=$ Colgate Total 12 Professional Whitening; L= Luminous White Advanced

\section{Discussion}

In buccal environment the composite resin is subjected to chemical and mechanical challenges that can alter its properties and expose its filler particles. This allows the incorporation of exogenous pigments, modifying their coloration and surface roughness ${ }^{8}$.

It is imposed that dental brushing may cause chemical-mechanical challenge to the composites, so this study evaluated the color change and surface roughness of two brands of Bulk Fill composites resin after mechanical brushing with three different whitening dentifrices, totaling 10,000 cycles, which are clinically equivalent to a period of approximately one year of dental brushing ${ }^{13}$.

The abrasiveness of the paste created by the dentifrice during brushing is influenced by physical characteristics of the abrasive particles, such as shape, size, and hardness. Consequently, thicker and irregular particles produce rougher surfaces and, since there are more abrasives in the whitening dentifrices responsible for the bleaching effect and, considering the brushing period, the surface color and surface roughness of the composites tested will be affected on a larger scale ${ }^{8}$.

The results of color variation showed that Filtek brushed with True White showed the highest color variation without statistical difference when the same resin was brushed with Colgate Total 12 Professional Whitening and with difference for the other groups. The Aura bulk fill resin did not show color variation when brushed with different whitening dentifrices. This result may be related to the composition of Filtek and dentifrices True White and Colgate Total 12 Professional Whitening. Filtek resin contains benzotriazole, an antibacterial monomer with a light yellow coloration. In a previous study, was observed that benzotriazole has antibacterial action on an experimental resin, however, the increase in the concentration of this monomer, decreased the degree conversion of the resin. As a consequence, there is greater water absorption, which degrades the ester bond of the methacrylate polymers, promoting color change of the material. The same may have occurred with Filtek resin causing damage on the performance of this material14.

True White and Colgate Total 12 Professional Whitening dentifrices have titanium dioxide (TiO2) as their composition. It was observed that the incorporation 
of TiO2 nanoparticles significantly increased the opalescence of composite resins $^{15}$. Thus; it is believed that during the brushing there was deposition of TiO2 on the surface of Filtek changing the opacity of the material and the initial color. However, it is emphasized that the color variation values obtained are less than 3.3. According to the literature this value of $\Delta \mathrm{E}$ although perceived by skilled operators are clinically acceptable ${ }^{16}$.

The results of the surface roughness test showed that the Aura bulk fill resin showed a significant statistical difference between the initial roughness (control) and final roughness after brushing with Colgate Total 12 Professional Whitening and Sensodyne True White.

Dental brushing can degrade the composite surface through a three-body wear process by removing the polymer matrix layer that is a smoother layer, exposing the filler particles, which are stiffer and more uneven. The toothbrush can also increase this effect of abrasion, since the brush bristles do not wear out the surface of the material as evenly as flat discs or rubber cups would do, in finishing and polishing procedures ${ }^{17}$.

The organic matrix of Filtek Bulk fill has UDMA in its composition, which is a less viscous and more flexible functional monomer than BisGMA, present in the Aura Bulk fill resin composition. Because it is stiffer and less flexible than UDMA, Bis-GMA produces fewer crosslinks; with the result that the copolymers containing BisGMA tend to have lower hardness, which is directly related to the degree of conversion and greater sorption of water. It can be concluded that the UDMA present in the organic matrix of Filtek Bulk fill resin plays an important role for wear resistance and lower surface roughness ${ }^{18-21}$.

The filler / matrix interface present in the composite resin is designed to chemically bond the matrix to the filler particles by means of a silane bonding agent. This location is subject to the formation of microcracks in which water can penetrate, causing degradation of the composite. The surface of the composites becomes susceptible to the formation of cracks resulting from chewing. Therefore, it is assumed that the exposure of the filler particles, caused by the brushing with whitening dentifrices, accelerates the degradation of the composites, compromising the polishing, and increasing the roughness 22,23 .

The difference in behavior between the Filtek and Aura resins in the surface roughness test can be explained by the composition. Filtek is a nanoparticulate resin formed by nanomers and nanoclusters, which are slightly nano-sized charge-free agglomerates, which reduce the interstitial spacing between the particles. Therefore, there is greater amount of charge in this composite, and consequently, better physical properties and better surface smoothness. During mechanical brushing, only the nano-sized particles are displaced while the nanoclusters remain in the resin matrix. In this way, it can be assumed that the composition of Filtek favored its better performance in relation to surface roughness 24,25

In conclusion, it was concluded that the color changing and surface roughness of Bulk Fill resins after brushing with whitening dentifrices are dependent on the interaction between the composition of the composite resin and the characteristics of the dentifrice. 


\section{References}

1. Ferracane JL. Resin composite--State of the art. Dent Mater. 2011 Jan;27(1):29-38. doi: 10.1016/j.dental.2010.10.020.

2. Park J, Chang J, Ferracane JL, IB Lee. How should composite be layered to reduce shrinkage stress: Incremental or bulk filling? Dent Mater. 2008 Nov;24(11):1501-5. doi: 10.1016/j.dental.2008.03.013.

3. Kapoor N, Bahuguna N, Anand S. Influence of composite insertion technique on gap formation. J Conserv Dent. 2016 Jan-Feb;19(1):77-81. doi: 10.4103/0972-0707.173205.

4. Bacuta S, Ilie N. Light transmittance and micro- mechanical properties of bulk fill VS. Conventionl resin based composites. Clin Oral Investig. 2014 Nov;18(8):1991-2000. doi: 10.1007/s00784-013-1177-y.

5. Ilie N, Bacuta S, Draenert M. Bulk-fill Resin-based Composites: An In Vitro Assessment of Their Mechanical Performance. Oper Dent. 2013 Nov-Dec;38(6):618-25. doi: 10.2341/12-395-L.

6. Kalliecharan D, Germscheid W, Price RB, Stansbury J, Labrie D. Shrinkage stress kinetics of Bulk Fill resin-based composites at tooth temperature and long time. Dent Mater. 2016 Nov;32(11):1322-1331. doi: 10.1016/j.dental.2016.07.015.

7. Harlow JE, Rueggeberg FA, Labrie D, Sullivan B, Price RB. Transmission of violet and blue light through conventional (layered) and bulk cured resin-based composites. J Dent. 2016 Oct;53:44-50. doi: 10.1016/j.jdent.2016.06.007.

8. Roselino Lde M, Chinelatti MA, Alandia Román CC, Pires-de-Souza Fde C.

Effect of Brushing Time and Dentifrice Abrasiveness on Color Change and Surface Roughness of Resin Composites. Braz Dent J. 2015 Oct;26(5):507-13. doi: 10.1590/0103-6440201300399.

9. Barbieri GM, Mota EG, Rodrigues-Junior SA, Burnett LH Jr. Effect of whitening dentifrices on the surface roughness of commercial composites. J Esthet Restor Dent. 2011 Oct;23(5):338-45. doi: 10.1111/j.1708-8240.2011.00426.x.

10. Amaral CM, Rodrigues JA, Erhardt MC, Araujo MW, Marchi GM, Heymann HO, et al. Effect of whitening dentifrices on the superficial roughness of esthetic restorative materials. J Esthet Restor Dent. 2006;18(2):102-8; discussion 109.

11. Heintze SD, Forjanic M, Ohmiti K, Rousson V. Surface deterioration of dental materials after simulated toothbrushing in relation to brushing time and load. Dent Mater. 2010 Apr;26(4):306-19. doi: 10.1016/j.dental.2009.11.152.

12. Roselino Lde M, Cruvinel DR, Chinelatti MA, Pires-de-Souza Fde C. Effect of brushing and accelerated ageing on color stability and surface roughness of composites. J Dent. 2013 Nov;41 Suppl 5:e54-61. doi: 10.1016/j.jdent.2013.07.005.

13. Wang L, Garcia FC, Amarante Araujo P, Franco EB, Mondelli RF. Wear resistance of packable resin composites after simulated toothbrushing test. J Esthet Restor Dent. 2004;16(5):303-14; discussion 314-5.

14. Centenaro CC, Rostirolla FV, Leitune VC, Parolo CF, Oligari FA, Saumel SM, et al. Influence of addition of 2-[3-(2H-benzotriazol-2-YL)- 4-hydroxyphenyl] ethyl methacrylate to an experimental adhesive system. Acta Odontol Latinoam. 2015 Apr;28(1):72-8. doi: 10.1590/S1852-48342015000100010.

15. Yu B, Ahn JS, Lim Jl, Lee YK. Influence of TiO2 nanoparticles on the optical properties of resin composites. Dent Mater. 2009 Sep;25(9):1142-7. doi: 10.1016/j.dental.2009.03.012.

16. Shamszadeh S, Sheikh-Al-Eslamian SM, Hasani E, Abrandabadi AN, Panahandeh N. Color Stability of the Bulk-Fill Composite Resins with Different Thickness in Response to Coffee/Water Immersion. Int J Dent. 2016;2016:7186140. doi: 10.1155/2016/7186140.

17. Bagheri R, Tyas MJ, Burrow MF. Subsurface degradation of resin-based composites. Dent Mater. 2007 Aug;23(8):944-51. 
18. Asmussen E, Peutzfeldt A. Influence of UEDMA, BisGMA e TEGDMA on selected mechanical properties of experimental resin composites. Dent Mater. 1998 Jan;14(1):51-6.

19. Barszczewska-Rybarek I, Jurczyk S. Structure-property relationships in dimethacrylate networks based on Bis-GMA, UDMA and TEGDMA. Dent Mater. 2009 Sep;25(9):1082-9. doi: 10.1016/j.dental.2009.01.106.

20. Sideridou I, Tserki V, Papanastasiou G. Study of water sorption, solubility and modulus of elasticity of light-cured dimethacrylate-based dental resins. Biomaterials. 2003 Feb;24(4):655-65

21. Rodrigues-Junior SA, Scherrer SS, Ferracane JL, Della Bona A. Microstructural characterization and fracture behavior of a microhybrid and a nanofill composite. Dent Mater. 2008 Sep;24(9):1281-8. doi: 10.1016/j.dental.2008.02.006.

22. Ferracane JL. Hygroscopic and hydrolytic effects in dental polymer networks. Dent Mater. 2006 Mar;22(3):211-22.

23. Whitehead SA, Shearer AC, Watts DC, Wilson NHF. Surface texture changes of a composite brushed with tooth whitening dentifrices. Dent Mater. 1996 Sep;12(5):315-8.

24. Attar $\mathrm{N}$. The effect of finishing and polishing procedures on the surface roughness of composite resin materials. J Contemp Dent Pract. 2007 Jan 1;8(1):27-35.

25. Yadav RD, Raisingani D, Jindal D, Mathur R. A Comparative Analysis of Different Finishing and Polishing Devices on Nanofilled, Microfilled, and Hybrid Composite: A Scanning Electron Microscopy and Profilometric Study. Int J Clin Pediatr Dent. 2016 Jul-Sep;9(3):201-8. 